\title{
Long Term Trend Analysis of Rainfall, Rainy Days and Drought for Sindh River Basin, Madhya Pradesh, India
}

\author{
P. S. Pawar*, Umakant Rawat, Ankit Yadav, Aniket Rajput, \\ Devendra Vasht and S. Nema
}

\author{
Department of Soil and Water Engineering, College of Agricultural Engineering, \\ JNKVV, Jabalpur, India
}

*Corresponding author

\begin{abstract}
A B S T R A C T
Keywords

Rainfall, Rainy days, Drought, Trend, SPI

Article Info

Accepted:

18 November 2020

Available Online:

10 December 2020

Regional spatiotemporal analysis of rainfall and drought has to gain much more attention under the climate change scenario worldwide. The present study was taken to analyze regional level long term trend analysis of rainfall, rainy days, and drought over the Sindh river basin. The nonparametric Mann-Kendall/modified Mann-Kendall test was used to analyze the trend of rainfall, rainy days, and SPI series of different timescales $(1,3,6,9$, and 12-month SPI series) at a 95\% confidence level. The trend analysis of rainfall and rainy days showed a significant decreasing trend for the north-eastern part of the basin. The results of the SPI trend analysis indicate that a large portion of the basin has a rising trend of drought. The findings of this study will provide assistance to the planner for regional level planning and implementing a sound policy against drought in the Sindh river basin.

\section{Introduction}

Climate change is becoming an alarming threat in the twenty-first century. Due to global warming, there is an overall increase in the occurrence of extreme events (Mishra and Singh, 2010). Among the extreme meteorological events, drought is difficult to characterize. Thus, it is very challenging to determine its onset, duration, intensity, spatial extent, and end (Vicente-Serrano et al., 2009). According to Bonaccorso et al., (2003) for a better understanding of the recent climatic fluctuation and occurrence of drought, it is advisable to study long-term series of

precipitation in regions with nonhomogeneous hydro-meteorological conditions. India is amongst the most susceptible drought-prone countries in the world and drought occurs at least once every three years in the last five decades (Mishra and Singh, 2010). Based on the results of several studies on rainfall trends over India indicated that there is no statistically significant decline and rising trend of mean rainfall (Kumar et al., 2010; Lakshmi Kumar et al., 2014). But, agreeing to some studies, there is a incidence of significant either rising or declining rainfall trend over a long period of time on a regional scale (Patra et al., 2012;
\end{abstract}


Gajbhiye et al., 2016). Pai et al., (2011), carried out a long-term series (1901-2003) of southwest monsoon seasonal SPI trend analysis and reported significant negative and positive trends over several districts of India. Saha et al., (2018) analyzed 158 years' time series of rainfall dataset across India and reported high spatial variability in rainfall anomaly and most importantly depicted the unlike the pattern in the rainfall distribution over different regions of India. In an enormous and diverse country like India, there exists a different cropping pattern, crops and hydro-meteorological conditions pose a great challenge for appropriate planning and management of natural resources. To address such problems there is a need to execute studies for understanding the behavior of climate at the regional level with fine spatial resolution. Therefore, the two objectives of the study are taken as (1) To assess the spatiotemporal variations of rainfall and drought; and (2) To examine the climate change signals using the trend analysis of rainfall and SPI time series.

\section{Study area and data used}

The study area is the catchment area of the Sindh river. Sindh river is a tributary of Yamuna river, passes through two states of India namely Madhya Pradesh and Uttar Pradesh. The river originates from the Vidisha District of Madhya Pradesh. In Madhya Pradesh, it flows through the districts of Guna, Shivpuri, Ashoknagar, Bhind, Gwalior, and Datia. The catchment area of the river covering 26,699 $\mathrm{Km}^{2}$ area and $461 \mathrm{Km}$ length in Madhya Pradesh. Major tributaries of Sindh are Pahuj, Mahuar, Kunwari, and Parbati. The areal extension of the Sindh river basin is from $21^{0} 17^{\prime} \mathrm{N}$ to $26^{0} 36^{\prime} \mathrm{N}$ and $74^{0}$ $02^{\prime} \mathrm{E}$ to $82^{0} 26^{\prime} \mathrm{E}$ encompassing eight districts as shown in Figure 1. Sindh basin is characterized by a subtropical climate and receives maximum rainfall from Jun to
September. The cropping patterns are influenced by monsoon rainfall.

Daily rainfall for the period of 1901 to 2019 (119 years) prepared by the Indian Meteorological Department (IMD) at a spatial resolution of $0.25^{\circ} \times 0.25^{\circ}$ grid was used for this study (Pai et al., 2014). The data set was complete and hence no need for gap filling was required. Thirty-eight grid points that cover the Sindh River Basin were considered in this study. According to IMD glossary, in India rainfall are stated in four seasons viz. summer (March - May), winter (January February), monsoon (Jun - September) and post-monsoon (October - December). Rainy days, monthly, seasonal, and annual rainfall series were prepared from daily rainfall data for thirty-eight grid points.

\section{Materials and Methods}

\section{Computation of standardize precipitation index (SPI)}

In this study, SPI at different timescale is calculated based on long-term gridded rainfall data (119 years, 1901 to 2019) for 38 grid points. For the calculation of SPI, the long term monthly precipitation dataset was prepared for 38 grid points. SPI, designed by McKee et al., (1993) is fitted to a gamma probability distribution to establish the relationship between probability and precipitation. Once the gamma probability distribution is fitted to long term monthly aggregated precipitation, then the fitted function is used to calculate the cumulative probability distribution of the data points. Finally, cumulative probability distribution transforms into a normal distribution so that the mean SPI is zero and the standard deviation is one for the location and desired period (Edwards and McKee, 1997). SPI calculated for different timescale used for monitoring the important condition for both 
hydrological and agricultural applications. In the present case, typically SPI for 1-month, 3month, 6-month, 9-month, 12-month are calculated. The detailed procedure for computation of SPI is available in Edwards and McKee, (1997). The drought classification adapted in the present study is given by Lloyd-Hughes and Saunders (2002), in which SPI values ranged from 1.50 to 1.99 denote very wet, 1.0 to 1.49 represent moderate wet, -0.99 to 0.99 represent near normal, and 2 to more represent extreme wet, whereas SPI values ranged from -1.0 to -1.49 denote moderate drought, -1.5 to -1.99 represent severe drought, and -2.0 to less represent extreme drought.

\section{Trend analysis using MK test}

Mann-Kendall test (MK) has been widely used for detecting the presence of trend in climatic time series data (Mann, (1945).The MK statistics $\mathrm{S}$ is given below:

$S=\sum_{i=1}^{N-1} \sum_{j=i+1}^{N} \operatorname{sgn}\left(x_{j}-x_{i}\right)$

Where, $x_{i}$ and $x_{j}$ are the consecutive data point for the $i^{\text {th }}$ and $j^{\text {th }}$ terms in rainfall data series, $N$ is the total number of data point in series and sgn term defined as

$$
\operatorname{sgn}\left(x_{j}-x_{i}\right)=\left\{\begin{array}{l}
+1, \text { if } x_{j}-x_{i}>1 \\
0, \text { if } x_{j}-x_{i}=0 \\
-1 \text { if } x_{j}-x_{i}<1
\end{array}\right.
$$

If $N$ is larger than 10 , then $S$ statistics is assumed to be asymptotically normal, with $E(S)=0$ and the variance of $S$ is expressed as

Variance $(S)=\frac{\left[N(N-1)(2 N+5)-\sum_{a=1}^{n} t_{a}\left(t_{a}-1\right)\left(2 t_{a}+5\right)\right]}{18}$

Where $N$ is the number of data points, $n$ is the number of tied groups, and $t_{a}$ is the number of data points in the $a^{\text {th }}$ group. The MK statistics $Z_{m k}$ is expressed as:

$$
Z_{m k}=\left\{\begin{array}{c}
\frac{s-1}{\sqrt{\operatorname{Variance}(S)}} \ldots \ldots \ldots \ldots \text { if } S>0 \\
0 \ldots \ldots \ldots \ldots \ldots \ldots \text { if } S=0 \\
\frac{S+1}{\sqrt{\operatorname{Variance}(S)}} \ldots \ldots \ldots \ldots \text { if } S<0
\end{array}\right\}
$$

A positive $Z_{m k}$ values indicates an upward trend while the negative values shows the downward trend. In this study, the significance of $Z_{m k}$ values were tested at $95 \%$ confidence level.

The Mann-Kendall test is directly applied to the time series whose data are serially independent and random in behavior. Yue and Wang, (2004) proposed the modified MK test with the ESS (Effective Sample Size) approach to exclude the effect of autocorrelation on trend analysis. It is executed with modification in variance which is calculated as

$\operatorname{Variance}(S)^{*}=\operatorname{Variance}(S) \frac{n}{n^{*}}$

Where, $n^{*}$ is the effective sample size. Matalas and Langbein (1962), gives expression for calculation of $n *$ :

$$
n^{*}=\frac{n}{1+2 \times\left\{\frac{\rho_{1}^{n+1}-n \rho_{1}^{2}+(n-1) \rho_{1}}{n\left(\rho_{1}-1\right)^{2}}\right\}}
$$

Where, $\rho_{1}$ is the lag-1 autocorrelation coefficient, as given by Salas et al., (1985) as,

$\rho_{k}=\frac{\frac{1}{(n-\bar{k})} \sum_{t=1}^{n-k}\left(x_{t}-\bar{x}_{t}\right)\left(x_{t+k^{-}}-\bar{x}_{t}\right)}{\frac{1}{n} \sum_{t=1}^{n}\left(x_{t}-\bar{x}_{t}\right)^{2}}$

Where, ${ }^{\bar{x}_{t}}=\frac{1}{n} \sum_{t=1}^{n} x_{t}$

The lag-1 sample serial correlation coefficients $\left(\rho_{1}\right)$ calculated from the sample data after removing the trend. The detrended time series is obtained by subtracting $Q_{\text {med }}$ from the time series $\left(x_{t}-Q_{\text {med }} * t, t=0,1,2,3\right.$, $\ldots . ., n-1)$. The value of $Q_{m e d}$ is obtained 
using Sen's slope estimator (Theil, 1949; Sen, 1968). The value of MK $Z_{m m k}$ statistics is then calculated by putting the value of modified variance $(S) *$ in equation 4 .

\section{Results and Discussion}

\section{Descriptive statistics of rainfall and rainy days over the Sindh River Basin}

Rainfall (monthly, seasonal and annual) and rainy days were averaged over the Sindh river basin for the entire period (1901-2019). Descriptive statistics such as mean, standard deviation (SD), and coefficient of variation (CV) of monthly, seasonal, annual, and rainy days were calculated for the whole period of 119 years (1901-2019) for the Sindh river Basin (Table 1).

According to IMD (IMD Glossary), a rainfall amount of $2.5 \mathrm{~mm}$ or more realized in a day is a rainy day. Mean annual rainfall over the basin is $790.31 \mathrm{~mm}$ with a standard deviation of $241.53 \mathrm{~mm}$ and a coefficient of variation of $30.56 \%$. The average monthly rainfall over the basin varied from $3.40 \mathrm{~mm}$ (April) to $259.28 \mathrm{~mm}$ (August). In the case of mean seasonal rainfall, the highest rainfall was observed in the monsoon season $(717.38 \mathrm{~mm})$ which accounts for $90.77 \%$ of the total mean annual rainfall in the basin and the lowest rainfall observed in the summer season (15.79 $\mathrm{mm})$. A similar pattern was also observed in the case of mean seasonal rainy days. The highest number of mean seasonal rainy days was observed in the monsoon season $(40.75$ days) which accounts for $87.28 \%$ of the mean annual rainy days and the lowest number of mean seasonal rainy days was observed in the summer season (1.68 days) over the basin. The mean monthly rainy days range from 0.34 days (April) to 14.29 days (August) over the basin. It indicates that the rainfall increases with the increase of rainy days. The mean annual rainy days over the basin was observed as 46.77 days with a coefficient of variation of $24.32 \%$. The statistics of the coefficient of variation indicate that the variability of rainfall decreases with the increase of rainfall over the basin.

\section{Results of Lag 1 Autocorrelation}

The lag 1 autocorrelation of rainfall and rainy days series were checked at a 5\% significance level and which are depicted in Fig. 2.

For annual rainfall, it was found that all grid points show insignificant lag 1 autocorrelation. Out of 38 grid points, 3 grid points had significant lag 1 autocorrelation for monsoon rainfall. Similarly, post-monsoon, winter, and summer rainfall showed significant lag 1 autocorrelation for 2, 4 and 1 grid point out of 38 grid points respectively. In the case of the annual rainy days, 6 grid points showed significant lag 1 autocorrelation out of 38 grid points. For seasonal rainy days, 3, 2, 3 and only 1 grid point showed significant lag 1 autocorrelation out of 38 grid points in monsoon, postmonsoon, winter, and summer season respectively. The MK test was directly applied for serially independent rainfall data for estimation of the trend, whereas the modified MK (MMK) test suggested by Yue and Wang, (2004)was only applied for the estimation of the trends of serially correlated data.

\section{Spatiotemporal trend analysis of seasonal, annual rainfall and rainy days}

Long term trend analysis for annual and seasonal rainfall and rainy days over the basin is represented in Fig. 3 and Fig. 4, respectively. Trend analysis of annual and monsoon rainfall showed that out of 38 grid points, 4 grid points (grid numbers 16, 29, 35, and 38) had a significant decline trend. There are $39.47 \%$ grid points that showed an 
insignificant decreasing trend and $50 \%$ grid points showed a non-significant rising trend during annual rainfall.

Similarly, $36 \%$ and $50 \%$ grid points showed a non-significant decline and rising trend respectively for rainfall during the monsoon season. The north-east part of the basin showed a declining trend for annual and monsoon rainfall. These results are in agreement with Kumar et al., (2010) who reported that, the decreasing trend of monsoon and annual rainfall for East part of Madhya Pradesh state.

Table.1 Statistical summary of monthly, seasonal, annual rainfall and rainy days of Sindh river basin (1901-2019)

\begin{tabular}{|l|c|c|c|c|c|c|}
\hline Month/ & \multicolumn{3}{|c|}{ Rainfall } & \multicolumn{3}{c|}{ Rainy days } \\
\cline { 2 - 7 } & $\begin{array}{c}\text { Mean } \\
(\mathrm{mm})\end{array}$ & $\begin{array}{c}\text { SD } \\
(\mathrm{mm})\end{array}$ & CV $(\%)$ & $\begin{array}{c}\text { Mean } \\
(\text { days })\end{array}$ & $\begin{array}{c}\text { SD } \\
\text { (days) }\end{array}$ & CV $(\%)$ \\
\hline January & 10.95 & 15.94 & 145.59 & 1.09 & 1.41 & 129.82 \\
\hline February & 9.14 & 16.20 & 177.33 & 0.89 & 1.38 & 155.15 \\
\hline March & 5.62 & 12.40 & 220.54 & 0.59 & 1.14 & 194.80 \\
\hline April & 3.40 & 10.32 & 303.35 & 0.34 & 0.83 & 247.58 \\
\hline May & 6.76 & 11.91 & 176.10 & 0.71 & 1.23 & 172.64 \\
\hline Jun & 70.12 & 70.66 & 100.77 & 4.86 & 3.51 & 72.17 \\
\hline July & 250.41 & 127.31 & 50.84 & 14.06 & 4.85 & 34.52 \\
\hline August & 259.28 & 132.46 & 51.09 & 14.29 & 5.04 & 35.26 \\
\hline September & 137.57 & 108.71 & 79.02 & 7.53 & 4.53 & 60.13 \\
\hline October & 25.46 & 48.58 & 190.85 & 1.40 & 2.00 & 143.04 \\
\hline November & 5.72 & 16.48 & 288.15 & 0.91 & 1.65 & 181.86 \\
\hline December & 5.87 & 14.73 & 250.84 & 0.56 & 1.10 & 196.65 \\
\hline Annual & 790.31 & 241.53 & 30.56 & 46.77 & 11.37 & 24.32 \\
\hline Monsoon & 717.38 & 228.44 & 31.84 & 40.75 & 10.19 & 25.02 \\
\hline Post- & 37.05 & 53.12 & 143.39 & 2.41 & 2.51 & 104.35 \\
\hline monsoon & & & & & & \\
\hline Winter & 20.09 & 23.19 & 115.43 & 1.98 & 1.98 & 1.98 \\
\hline Summer & 15.79 & 21.12 & 133.79 & 1.64 & 2.02 & 123.38 \\
\hline
\end{tabular}

Table.2 Drought properties of SPI series over the Sindh river basin

\begin{tabular}{|c|c|c|c|c|c|}
\hline \multirow{2}{*}{$\begin{array}{l}\text { SPI } \\
\text { series }\end{array}$} & \multirow{2}{*}{$\begin{array}{l}\text { Number of drought } \\
\text { month }(\mathrm{SPI}<-1) \\
(1901-2019)\end{array}$} & \multirow{2}{*}{$\begin{array}{l}\text { Number of } \\
\text { drought } \\
\text { incidences }\end{array}$} & \multicolumn{3}{|c|}{ Duration of drought months } \\
\hline & & & Minimum & Maximum & Average \\
\hline SPI-1 & 63 & 53 & 1 & 3 & 1.18 \\
\hline SPI-3 & 144 & 85 & 1 & 6 & 1.69 \\
\hline SPI-6 & 160 & 71 & 1 & 7 & 2.25 \\
\hline SPI-9 & 151 & 59 & 1 & 10 & 2.55 \\
\hline SPI-12 & 143 & 34 & 1 & 13 & 3.32 \\
\hline
\end{tabular}


Table.3 Trend analysis of SPI multi timescale series in the study area

\begin{tabular}{|c|c|c|c|c|c|}
\hline Grid Number & 1- Month SPI & 3- Month SPI & 6- Month SPI & 9- Month SPI & 12- Month SPI \\
\hline 1 & -1.90 & -1.35 & -1.01 & -0.76 & -0.59 \\
\hline 2 & -1.59 & -1.17 & -0.71 & -0.42 & -0.34 \\
\hline 3 & -0.87 & -0.78 & -0.41 & -0.07 & -0.04 \\
\hline 4 & -1.70 & -1.14 & -0.45 & 0.19 & 0.21 \\
\hline 5 & -0.32 & -0.18 & 0.38 & 0.95 & 0.80 \\
\hline 6 & 0.34 & -0.08 & -0.04 & 0.16 & 0.05 \\
\hline 7 & -0.72 & -1.18 & -1.09 & -0.70 & -0.59 \\
\hline 8 & -0.04 & -0.56 & -0.30 & -0.05 & -0.06 \\
\hline 9 & -0.76 & -1.14 & -1.06 & -0.80 & -0.68 \\
\hline 10 & 0.29 & -0.41 & -0.66 & -0.61 & -0.48 \\
\hline 11 & -0.29 & -0.46 & -0.27 & -0.11 & -0.25 \\
\hline 12 & -0.47 & -0.65 & -0.03 & 0.29 & 0.22 \\
\hline 13 & 0.81 & 0.24 & 0.54 & 0.86 & 0.68 \\
\hline 14 & 1.45 & 0.87 & 0.92 & 1.05 & 0.87 \\
\hline 15 & 0.83 & 0.56 & 0.34 & 0.29 & 0.18 \\
\hline 16 & -2.26 & -2.49 & -2.68 & -2.54 & -1.86 \\
\hline 17 & -1.31 & -1.36 & -1.34 & -1.11 & -0.95 \\
\hline 18 & 0.65 & 0.02 & 0.24 & 0.37 & 0.20 \\
\hline 19 & 1.70 & 0.65 & 0.81 & 0.90 & 0.64 \\
\hline 20 & 1.74 & 1.15 & 1.40 & 1.43 & 1.09 \\
\hline 21 & 1.36 & 1.10 & 1.07 & 1.06 & 0.84 \\
\hline 22 & -0.25 & -0.44 & -0.61 & -0.63 & -0.55 \\
\hline 23 & -0.62 & -0.66 & -0.40 & -0.16 & -0.16 \\
\hline 24 & 1.08 & 0.25 & 0.07 & -0.02 & -0.05 \\
\hline 25 & 3.41 & 1.38 & 0.87 & 0.63 & 0.31 \\
\hline 26 & 2.46 & 1.33 & 1.11 & 1.04 & 0.71 \\
\hline 27 & 1.07 & 0.80 & 0.70 & 0.60 & 0.41 \\
\hline 28 & -0.55 & -0.63 & -0.87 & -0.98 & -0.80 \\
\hline 29 & -2.96 & -2.65 & -2.75 & -2.77 & -2.17 \\
\hline 30 & 1.99 & 0.97 & 0.66 & 0.56 & 0.36 \\
\hline 31 & 2.12 & 0.75 & 0.37 & 0.17 & 0.05 \\
\hline 32 & 1.03 & 0.58 & 0.63 & 0.67 & 0.42 \\
\hline 33 & 1.57 & 1.57 & 1.54 & 1.41 & 0.97 \\
\hline 34 & -0.14 & -0.48 & -0.66 & -0.80 & -0.69 \\
\hline 35 & -2.60 & -2.32 & -2.36 & -2.25 & -1.75 \\
\hline 36 & -0.51 & -1.01 & -1.35 & -1.52 & -1.34 \\
\hline 37 & -1.15 & -1.13 & -1.25 & -1.22 & -0.96 \\
\hline 38 & -1.28 & -1.61 & -1.92 & -1.91 & -1.50 \\
\hline
\end{tabular}

Bold values indicates significant trend at the 5\% significant level 
Fig.1 Location map of Sindh river basin

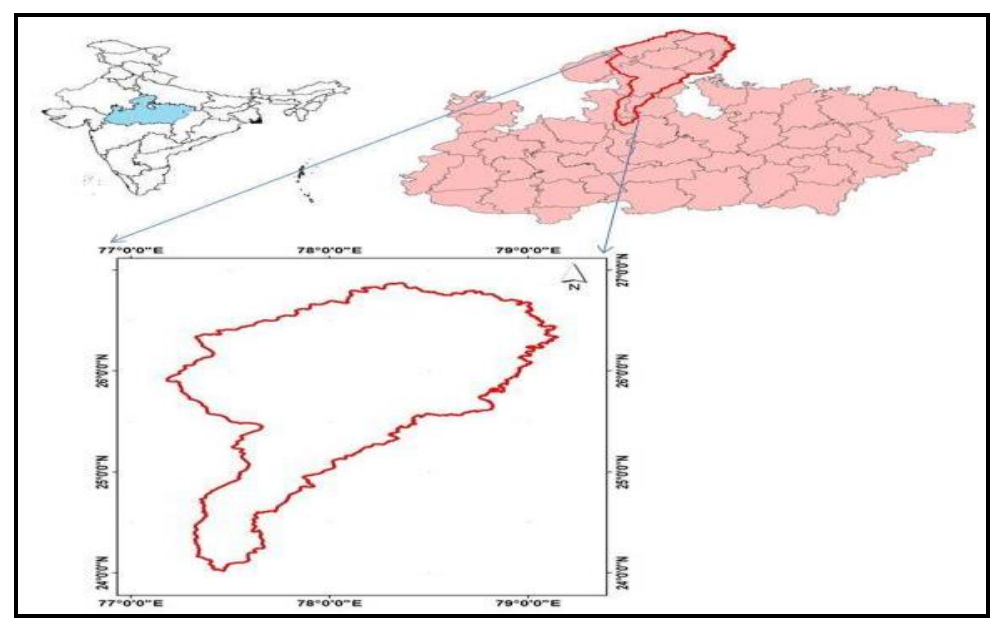

Fig.2 Lag 1 autocorrelation annual and seasonal rainfall and rainy days
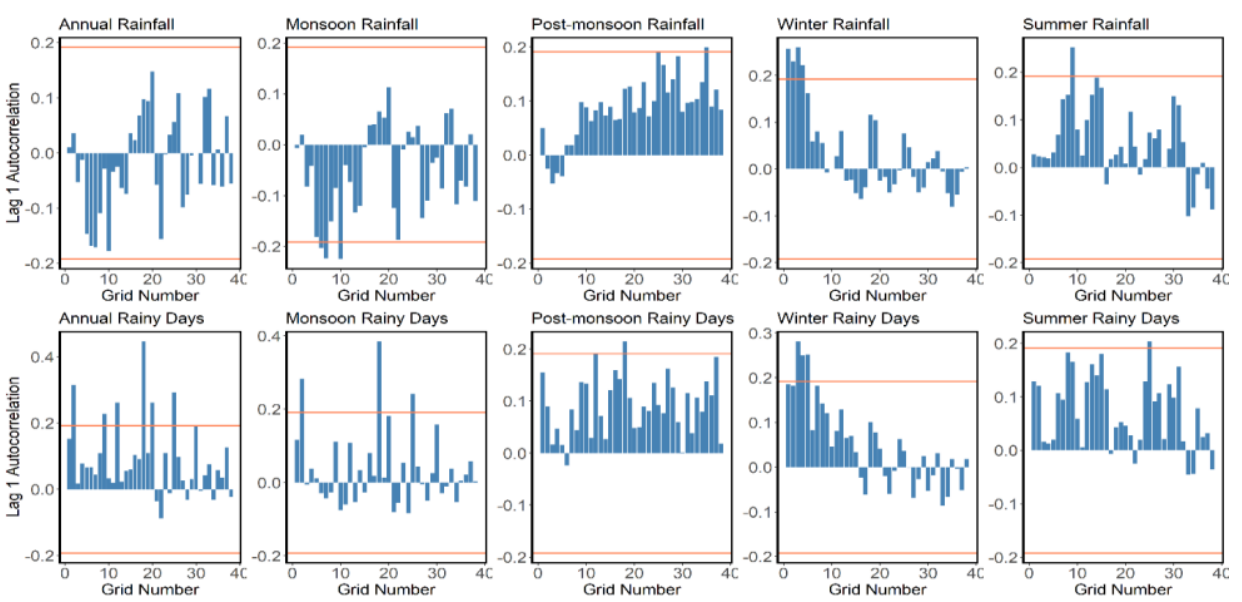

Fig.3 Rainfall trend for annual and seasonal rainfall over the Sindh river basin
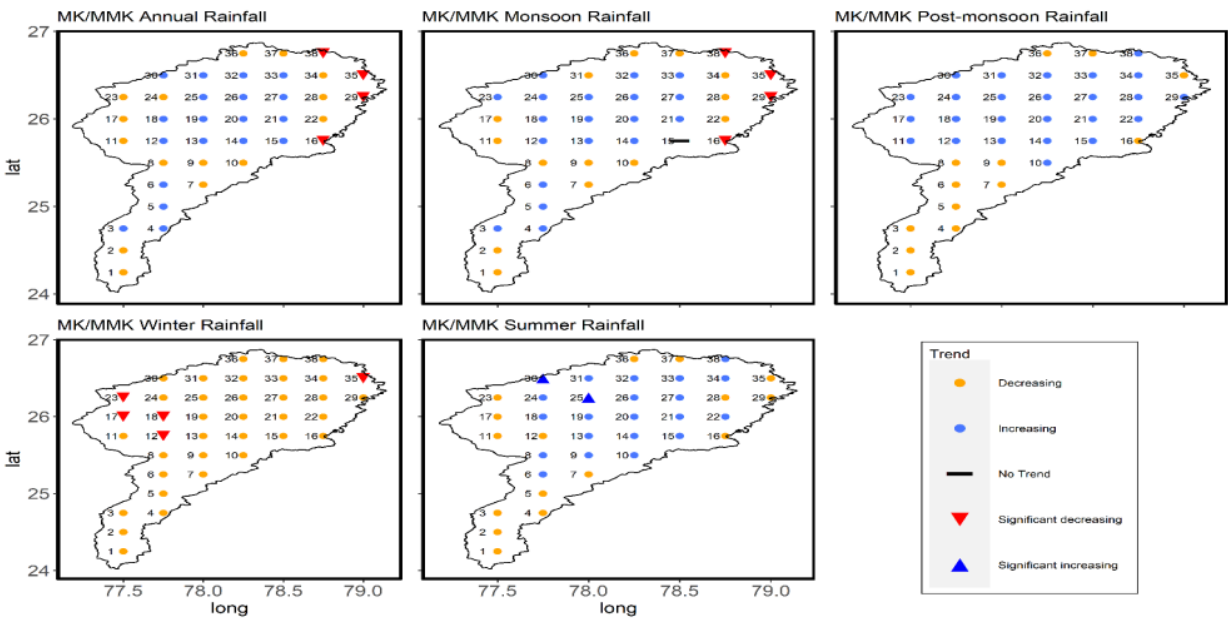

MK/MMK Summer Rainfall
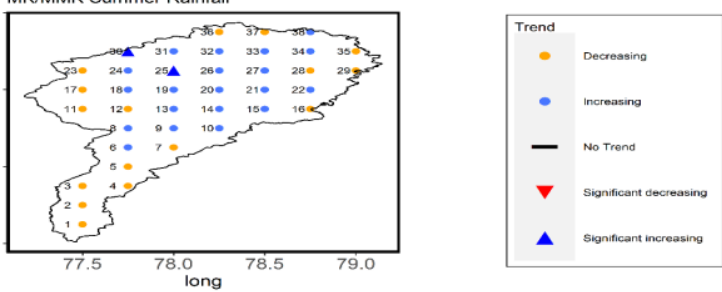
Fig.4 Rainy days trend for annual and seasonal rainfall over the Sindh river basin
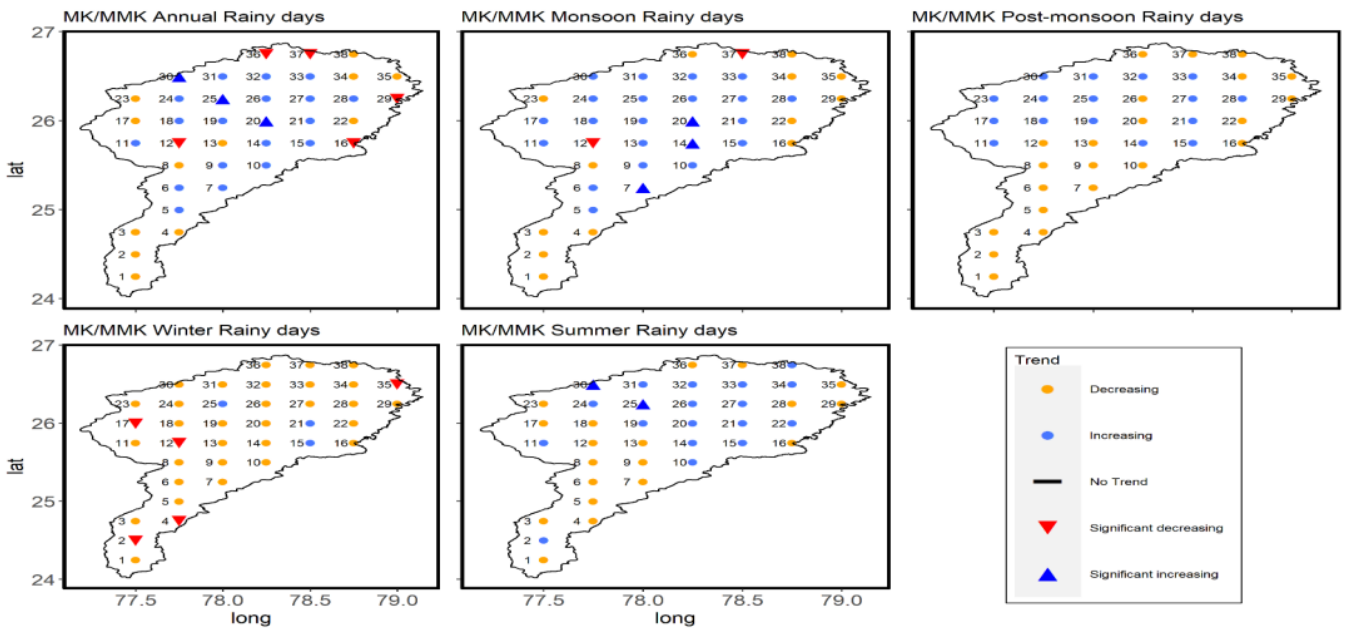

MK/MMK Summer Rainy days
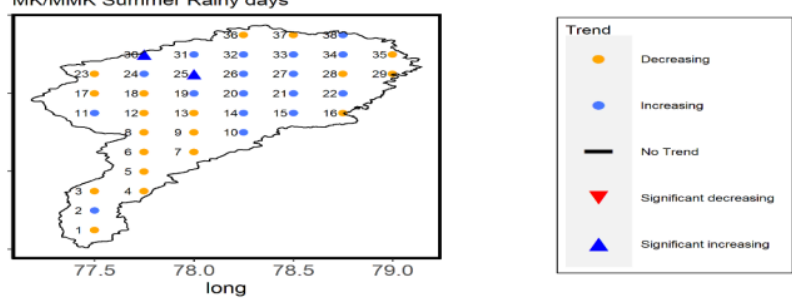

Fig.5 Temporal variation of SPI over the Sindh river basin

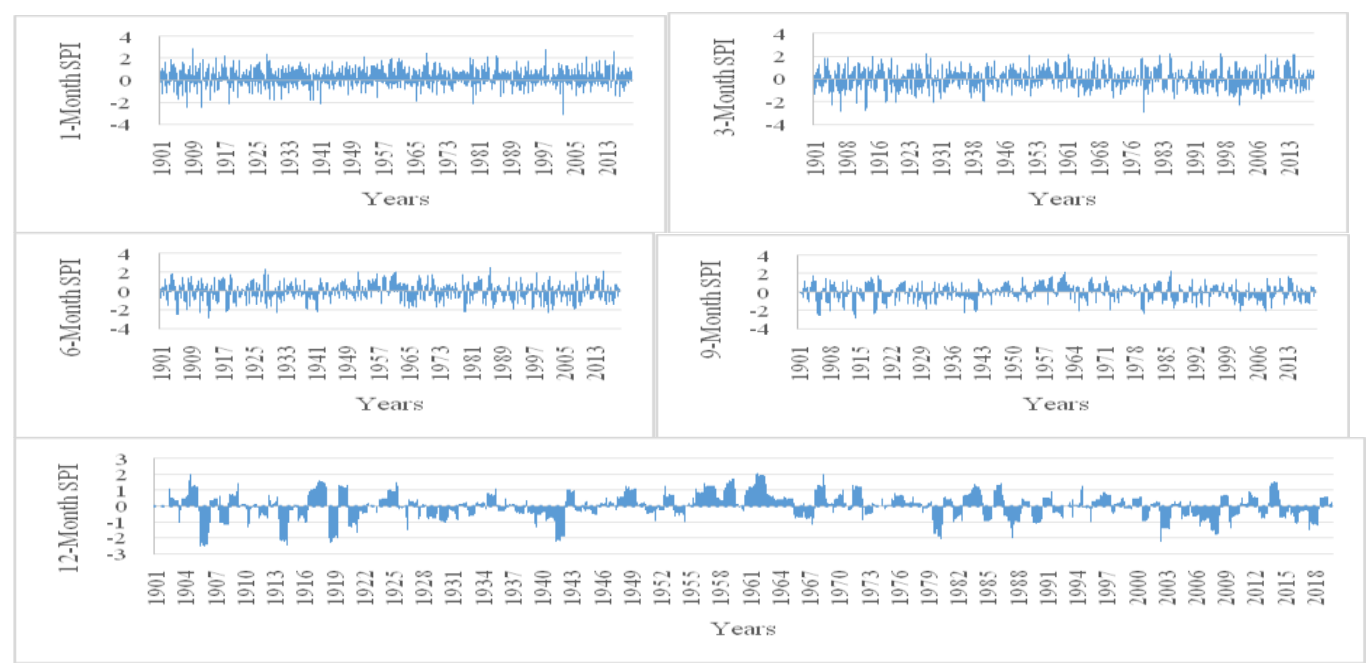

During the post-monsoon season, there is an insignificant either increasing $(65.79 \%$ grid point) or decreasing (34.21\% grid point) rainfall trend. While in the winter season, all grid points showed a declining trend and among them, only 5 grid points $(12,17,18$, 23, and 35) showed a significant decreasing trend. Out of 38 grid points, only two grid points showed a significant rising trend, whereas others showed either insignificant rising $(52.63 \%$ grid point) or decline $(42.10 \%$ grid point) rainfall trends during the summer season.
For understanding the distribution of rainfall over the basin, a trend analysis of rainy days was also carried out for all grid points. A significant rising trend for annual rainy days was observed at only 3 grid points (Grid numbers 20, 25, and 30) while a significant decline trend for annual rainy days was observed at 5 grid points (Grid numbers 12, 16, 29, 36 and 37). Likewise, during the monsoon season, there was a significant increasing trend of rainy days for 3 grid points (Grid numbers 7, 14, and 20) whereas two grid points (Grid numbers 12 and 37) 
showed a significant decline trend for rainy days. For the post-monsoon season, there was an insignificant either rising $(42.11 \%$ grid point) or decline $(57.89 \%$ grid points) trend for rainy days was found.

The lower part of the basin had a declining trend during the post-monsoon season. Thirtyfive grid points out of 38 grid points showed a declining trend for rainy days with 5 grid points exhibited a significant decline trend during the winter season. Only two grid points (Grid number 25 and 30) showed a significant increasing trend for rainy days during the summer season while $50 \%$ and $44.74 \%$ grid points showed non-significant declining and rising rainy days trend in the summer season respectively.

From the results of the rainfall trend analysis, it is noticed that the annual rainfall and monsoon rainfall resemble similar patterns of the trend. It mainly because monsoon rainfall contributes a major share of annual rainfall. From Fig. 3 and 4, the central part of the basin had an increasing trend for both rainfall and rainy days in all seasons except the winter season. A notably strong relation between rainfall and rainy days was observed over the basin. The results of the long term trend analysis of rainfall are in agreement with the studies conducted in Madhya Pradesh byDuhan and Pandey,(2013) and Jana et al., (2017).

\section{Influence of SPI time scales on drought characteristics}

The SPI of different time scales influenced the characteristics of drought such as duration and frequency of drought. From Fig. 5, it is illustrated that 1-month SPI had a higher frequency of droughts with sudden shifting between wet and dry conditions, whereas it has a very short duration. The frequency of droughts decreases with an increase in time scale (such as 6-month, 9-month, and 12month SPI) but the duration of the drought increases accordingly. The drought properties such as the number of drought months and its incidences along with its duration are presented in Table 2. The maximum number of drought incidence was found for the SPI-3 series, whereas the minimum number of drought incidence was found for the SPI-12 series. It was found that, the total number of drought months varying from 63 months (SPI-1 series) to 160 months (SPI-6 series) for the entire period over the basin. The maximum duration of the drought was 13 months in the case of the SPI-12 series, followed by SPI-9, SPI-6, SPI-3, and SPI-1 with the duration of $10,7,6$, and 3 months respectively. Similarly, the average drought duration for the SPI-12 series was 3.32 months followed by SPI-9, SPI-6, SPI-3, and SPI-1 with an average duration of $2.55,2.25$, 1.69 , and 1.18 months respectively.

The number of extreme droughts occurred over the basin during the different time scales of SPI for the entire period. SPI- 1 month showed 7 extreme drought events over the basin. Similarly, 3-month SPI showed 14 extreme drought events over the basin. Twenty-eight extreme drought events were observed for the SPI-6 month series. Likewise, thirty-two and thirty-five extreme drought events were noticed for SPI-9 and SPI-12 months over the basin respectively.

\section{Spatiotemporal trend analysis of SPI}

The computation of SPI consists of the aggregation of rainfall data at different time scales. Due to which the SPI series possess inherent autocorrelation. Therefore the modified Mann-Kendall test (MMK) is applied for trend analysis of SPI series because it eliminates the effect of autocorrelation. Amirataee and Montaseri, (2017) reported that the modified Mann- 
Kendall test has a relative advantage in drought trend analysis as compared to the basic Mann-Kendall test. Table 3 presenting the trends of drought intensity in the Sindh river basin according to SPI-1, SPI3, SPI-6, SPI-9, and SPI-12, calculated by the Modified Mann-Kendall test. Table 3 showed that a statistically significant rising trend was observed at the grid number of 25,26 , and 31 only in the case of SPI-1 time series among the different SPI time scale. However, grid numbers 16, 29, and 35 showed a significant declining trend for SPI-1, SPI-3, SPI-6, and SPI-9 time series over the basin. In addition to grid numbers 16,29 , and 35 , grid number 38 also showed a significant declining trend for the SPI-6 series. For the 12-month SPI series, a statistically significant declining trend was found at grid number 29 only. The other grid points of the 12-month SPI series either showing non-significant rising $(47.37 \%$ grid points) or declining ( $50 \%$ grid points) trend over the basin. In the case of the SPI-1 trend, $47.37 \%$ of grid points showed a nonsignificant decreasing trend whereas $36.84 \%$ of grid points showed an insignificant rising trend over the basin. Similarly, for the SPI-3 series, $52.63 \%$ grid points showed a nonsignificant negative trend while $39.47 \%$ grid points exhibited a non-significant positive trend. The $47.37 \%$ grid points showed an insignificant negative trend and $42.10 \%$ grid points showed an insignificant positive trend in the case of SPI-6 trend over the basin. Likewise, SPI-9 trend exhibited $47.37 \%$ grid points had non-significant increasing trend and $44.74 \%$ grid points had non-significant decreasing trend over the basin. By the overall spatial pattern of the trend of SPI, it was noticed that the northeast part of the basin especially four grid points i.e. grid numbers $16,29,35$, and 38 are more prone to drought in the basin. Also, it was noticed that there is strong agreement between rainfall trend, rainy days trend, and SPI trend over the basin. Similar kinds of results were obtained by Das et al., (2020) for Luni river basin in Rajasthan, India.

In conclusion the study presents the long term spatiotemporal trend analysis of rainfall, rainy days, and drought over the Sindh river basin. The results of the nonparametric MannKendall/Modified Mann-Kendall test revealed that the north-east part of the basin experienced significant declining trends for rainfall and rainy days. It indicates that the north-east part of the basin needs immediate effective management practices to alleviate drought in the future. In the winter season, almost all grid points showed a decreasing trend for rainfall, and rainy days poses a serious problem to agriculture over the Sindh river basin. It was noticed that, as the time scale increases the incidences of drought decrease with an increase in drought duration i.e. fewer drought events last for a longer duration. The spatial and temporal trend analysis of rainfall, rainy days, and drought can help policymakers to understand the behavior of rainfall and drought patterns over the Sindh river basin and accordingly to build planning and mechanism to deals with the drought effectively.

\section{Acknowledgment}

The authors are thankful to National Agriculture Higher Education Project (NAHEP), Centre for Advanced Agricultural Science and Technology on "Skill development to use spatial data for natural resources management in agriculture", Department of Soil and Water Engineering, College of Agricultural Engineering, JNKVV, Jabalpur for providing financial and other support.

\section{References}

Amirataee, B., and Montaseri, M.2017. The performance of SPI and PNPI in 
analyzing the spatial and temporal trend of dry and wet periods over Iran. Nat Hazards 86:89-106.

Bonaccorso, B., Bordi, I., Cancelliere, A., G. Rossi and A. Sutera 2003. Spatial Variability of Drought: An Analysis of the SPI in Sicily. Water Resources Management 17:2 73-296.

Das, J., Gayen, A., Saha, P., and Bhattacharya, S. K. 2020. Meteorological drought analysis using Standardized Precipitation Index over Luni River Basin in Rajasthan, India. SN ApplSci 2:1530.

Duhan, D., and Pandey, A. 2013. Statistical analysis of long term spatial and temporal trends of precipitation during 1901-2002 at Madhya Pradesh, India. Atmospheric Research 122:136-149.

Edwards, D.C., and McKee, T. B. 1997. Characteristics of 20th Century Drought in the United States at Multiple Scales. Atmospheric Science Paper No. 634, May 1-30.

Gajbhiye, S., Meshram, C., Mirabbasi, R., and Sharma, S. K.2016. Trend analysis of rainfall time series for Sindh river basin in India. TheorApplClimatol 125:593-608.

IMD, Meteorological terminologies and glossary; India Meteorological Department http://www.imdpune.gov.in /Weather/Reports/glossary.pdf.

Jana, C., Alam,N. M., Mandal, D. and Mohammad, S. 2017.Spatio-temporal rainfall trends in the twentiethcentury for Bundelkhand region, India. Journal of Water and Climate Change8:441455.

Kumar, V., Jain, S. K., and Singh, Y.2010. Analysis of long-term rainfall trends in India. Hydrological Sciences Journal 55:484-496.

Lakshmi Kumar, T. V., Koteswara Rao, K., Barbosa, H., and Uma, R. 2014. Trends and extreme valueanalysis of rainfall pattern over homogeneous monsoon regions of India. Nat Hazards 73:1003-1017.

Lloyd-Hughes, B., and Saunders, M. 2002. A Drought Climatology for Europe. International Journal of Climatology 22:1571-1592.

Mann, H. B.1945. Nonparametric Tests Against Trend. Econometrica 13:245259.

Matalas, N. C., and Langbein, W. B. 1962. Information content of the mean. Journal of Geophysical Research (1896-1977) 67:3441-3448.

McKee, T. B., Doesken, N. J., and Kleist, J. 1993. The relationship of drought frequency and duration to time scales. In: Proceedings of the $8^{\text {th }}$ Conference on Applied Climatology, American Meteorological Society, Boston, MA, USA, Anaheim, California, vol. 17, pp $179-183$

Mishra, A. K., and Singh, V. P. 2010. A review of drought concepts. Journal of Hydrology 391:202-216.

Pai, D. S., Sridhar, L., Guhathakurta, P., andHatwar, H. R. 2011. District-wide drought climatology of the southwest monsoon season over India based on standardized precipitation index (SPI). Nat Hazards 59: 1797-1813.

Pai, D.S., Sridhar, L., Rajeevan, M., Sreejith, O.P., Satbhai, N.S., and Mukhopadhyay, B. 2014. Development of a new high spatial resolution $\left(0.25^{0}\right.$ x $0.25^{0}$ ) long period (1901-2010) daily gridded rainfall data set over India and its comparison with existing data sets over the region. Mausam 65, 1-18.

Patra, J. P., Mishra, A., Singh, R., and Raghuwanshi, N. S. 2012. Detecting rainfall trends in twentieth century (1871-2006) over Orissa State, India. Climatic Change 111:801-817.

Saha, S., Chakraborty, D., Paul, R. K., Sandipan, S., and Singh, S. B.2018. 
Disparity in rainfall trend and patterns among different regions: analysis of 158 years' time series of rainfall dataset across India. Theor Appl Climatol., 134:381-395.

Salas, J. D., Delleur, J. W., and Yevjevich, V. 1985. Applied Modeling of Hydrologic Time Series. Water Resources Publications.

Sen, P. K.1968. Estimates of the Regression Coefficient Based on Kendall's Tau. Journal of the American Statistical Association, 63:1379-1389.

Theil, H. 1949.A rank invariant method of linear and polynomial regression analysis, Part 3. Nederl. Akad. Wetensch. Proc. 53, 1397-1412.

Vicente-Serrano, S. M., Beguería, S., and López-Moreno, J. I. 2009. A Multiscalar Drought Index Sensitive to Global Warming: The Standardized Precipitation Evapotranspiration Index. J Climate, 23: 1696-1718.

Yue, S., and Wang, C.2004. The MannKendall Test Modified by Effective Sample Size to Detect Trend in Serially Correlated Hydrological Series. Water Resources Management, 18: 201-218.

\section{How to cite this article:}

Pawar, P. S., Umakant Rawat, Ankit Yadav, Aniket Rajput, Devendra Vasht and Nema, S. 2020. Long Term Trend Analysis of Rainfall, Rainy Days and Drought for Sindh River Basin, Madhya Pradesh, India. Int.J.Curr.Microbiol.App.Sci. 9(12): 2738-2749.

doi: https://doi.org/10.20546/ijcmas.2020.912.327 